\title{
A Regret Theory of Capital Structure*
}

\author{
Kit Pong Wong ${ }^{\dagger}$ \\ University of Hong Kong
}

December 2014

\begin{abstract}
This paper examines the optimal capital structure of a firm that delegates its financing decision of a risky project to a manager who is both risk averse and regret averse. Regret aversion is characterized by a utility function that includes disutility from having chosen ex-post suboptimal alternatives. We show that the manager optimally opts for zero leverage if risk aversion is relatively more important than regret aversion in representing the manager's preferences. Otherwise, the optimal capital structure is interior such that the optimal amount of debt increases when regret aversion becomes increasingly more important than risk aversion in representing the manager's preferences. We further show that the firm's market leverage ratio is inversely related to the project's profitability and to the firm's market-to-book ratio. These comparative static results are consistent with the robust evidence documented in the literature on empirical capital structure.
\end{abstract}

JEL classification: D21; D81; G21

Keywords: Capital structure; Managerial preferences; Regret theory

${ }^{*}$ I would like to thank Udo Broll, Hui Chen (Co-Editor), Ramazan Gensçay (Editor-in-Chief), Paul Hsu, Yusuke Osaki, Peter Welzel, seminar participants at the University of Augsburg, and an anonymous referee for their helpful comments and suggestions. The usual disclaimer applies.

${ }^{\dagger}$ Correspondence to: Kit Pong Wong, School of Economics and Finance, University of Hong Kong, Pokfulam Road, Hong Kong. Tel.: 852-2859-1044; fax: 852-2548-1152; e-mail: kpwong@econ.hku.hk (K. P. Wong). 


\section{Introduction}

Since the seminal work of Modigliani and Miller (1958), there has been a huge literature on corporate finance that studies how firms choose their capital structure. One important strand of this literature is the static trade-off theory wherein firms have interior optimal capital structure that strikes a balance between interest tax-shield benefits and bankruptcy costs of debt. This theory, albeit intuitive, has received mixed empirical support. As surveyed in Graham and Leary (2011), the static trade-off theory appears to be consistent with a broad range of stylized facts. For example, low-volatility firms and firms with more tangible assets tend to borrow more. However, Graham and Leary (2011) also point out that this theory fails on at least as many other grounds. For example, firms issue far less debt than predicted by the theory, thereby rendering the so-called "debt conservatism" (Graham, 2000; Korteweg, 2010) and "zero-leverage puzzle" (Strebulaev and Yang, 2013). ${ }^{1}$ Most troubling of all is the robust evidence that profitable firms have low leverage even though these firms seem to have low likelihood of financial distress and obvious need to shield their income from corporate taxation. As Myers (1993) states, "The most telling evidence against the static trade-off theory is the strong inverse correlation between profitability and leverage."

Using a survey-based approach, Graham et al. (2013) provide convincing evidence that CEO's behavioral traits such as managerial risk aversion and optimism are related to corporate financial policies. Using a manager-firm matched panel data, Bertrand and Schoar (2003) find that manager fixed effects can explain a significant extent of the heterogeneity in leverage. The purpose of this paper as such is to incorporate managerial attitudes into the theories of capital structure. To this end, we develop a variant model of Blazenko (1987) wherein existing shareholders delegate their financing decision of a risky project to a manager whose preferences are abided by not only risk aversion but also regret aversion.

\footnotetext{
${ }^{1}$ Alemida and Philippon (2007) find that financial distress costs can help explain why firms use debt conservatively (see also Molina, 2005). Chen (2010) provides another risk-based explanation by introducing macroeconomic conditions into firms' financing decisions.
} 
Regret aversion indicates the managerial desire to avoid consequences wherein the manager appears to have made ex-post suboptimal decisions even though those decisions are ex-ante optimal based on the information available at that time. Bell $(1982,1983)$ and Loomes and Sugden (1982) define regret as the disutility arising from not having chosen the ex-post optimal alternative. Quiggin (1994) and Sugden (1993) provide an axiomatic foundation of regret theory, which is supported by extensive experimental studies that document regret-averse preferences among individuals (see, e.g., Loomes, 1988; Loomes et al., 1992; Loomes and Sugden, 1987; Starmer and Sugden, 1993). ${ }^{2}$

In this paper, we follow the regret-theoretical approach of Braun and Muermann (2004), Michenaud and Solnik (2008), and Wong (2014) to characterize managerial preferences by a modified utility function that includes disutility from having chosen ex-post suboptimal alternatives. Regret is measured by the difference between the actual wealth and the maximum wealth that the existing shareholders could have received should the manager have made the optimal financing decision based on knowing the project's true cash flow. Regret aversion is modeled by a convex function defined over the magnitude of regret. ${ }^{3}$ To capture the co-existence of managerial risk aversion and regret aversion, we specify the manager's modified utility function as a weighted average of a concave utility function and a convex regret function.

If the manager is solely risk averse, we show that all-equity financing is optimal from the manager's perspective. This zero-leverage outcome is driven by the manager's riskminimizing incentive because issuing debt always gives rise to mean-preserving-spread increases in risk (Rothschild and Stiglitz, 1970) in the existing shareholders' wealth. Managerial risk aversion then implies the optimality of all-equity financing (Rothschild and Stiglitz, 1971). This result is consistent with the zero-leverage behavior prevalent in the U.S. (Strebulaev and Yang, 2013) and in many developed countries (Bessler et al., 2013).

\footnotetext{
${ }^{2}$ Steil (1993) conducts a survey of 26 multinational firms in the U.S. regarding their foreign exchange risk management. Most respondents in his survey strongly object to the hedging strategies as suggested by expected utility maximization because they regard those strategies as ex-post suboptimal ones, which is consistent with regret theory.

${ }^{3}$ Bleichrodt et al. (2010) provide empirical evidence that regret functions are indeed convex.
} 
In the general case that the manager is both risk averse and regret averse, we show that the optimal capital structure is the one that jointly minimizes the variability of the existing shareholders' wealth and that of the manager's regret. While the risk-minimizing incentive induces the manager to opt for zero leverage, the regret-minimizing incentive induces the manager to avoid making extreme financing decisions. As a result, the manager optimally opts for an interior choice of capital structure such that the optimal amount of debt increases when regret aversion becomes increasingly more important than risk aversion in representing the manager's preferences.

Finally, we derive a closed-form solution in the case that the manager is solely regret averse and the project's risky cash flow is binary. When the firm is more profitable or has a higher market-to-book ratio, the existing shareholder's wealth is closer to (further away from) the maximum wealth should the project succeed (fail). To minimize regret, the manager optimally issues less debt so as to lower the magnitude of regret in the failure state and raise that in the successful state. Hence, the firm's market leverage ratio is inversely related to its profitability and market-to-book ratio. These comparative static results are consistent with the findings in the literature on empirical capital structure (Graham and Leary, 2011).

Employing either direct survey responses or indirect empirical proxies to identify managerial risk aversion and regret aversion, we can test the following model implications. (1) The likelihood of zero leverage is negatively associated with the importance of regret aversion relative to risk aversion in representing managerial preferences. (2) Market leverage ratios are positively associated with the importance of regret aversion relative to risk aversion in representing managerial preferences. ${ }^{4}$ (3) After controlling for asymmetric information and moral hazard factors, market leverage ratios remain to be negatively associated with profitability and with market-to-book ratios.

\footnotetext{
${ }^{4}$ A caveat against predications (1) and (2) is the presumption of complete capital markets. As shown by Chen et al. (2010), more risk-averse entrepreneurs may choose higher leverage for risk-sharing purposes when capital markets are incomplete.
} 
This paper is related to Blazenko (1987) that considers risk-averse managers making debt versus equity decisions on behalf of existing shareholders to finance risky projects with binary outcomes. Blazenko (1987) shows that payoffs to existing shareholders under debt financing are simply mean-preserving-spreads of those under equity financing. Managers, being risk averse, find equity financing optimal in minimizing risk. ${ }^{5}$ When managers have private information that outside investors do not have, Blazenko (1987) shows that rational expectations equilibria exist in which managers of firms with high-quality projects signal their projects with debt so long as they are sufficiently risk averse. Managers of firms with low-quality projects have no incentives to misrepresent their projects by using debt because doing so creates excessive risk (see also Ross, 1977, 1978).

This paper is also related to a burgeoning recent literature that examines how managerial behavioral biases affect capital structure choices. Hackbarth $(2008,2009)$ shows that optimistic managers perceive equity to be more undervalued than debt by the market while overconfident managers have the opposite perception. Conditional on issuing debt, Hackbarth $(2008,2009)$ shows that biased managers choose higher levels of financial leverage and issue new debt more often than unbiased managers. Malmendier et al. (2011) empirically document that optimistic managers use leverage more aggressively. Using a survey-based approach, Graham et al. (2013) find that optimistic managers are likely to have more debt, in particular more short-term debt.

This paper contributes to the managerial approach of capital structure by showing that the relative importance of regret aversion to risk aversion in representing managerial preferences plays a crucial role in rationalizing debt conservatism and zero-leverage puzzle. We show further that regret aversion alone suffices to explain the robust inverse relation between leverage and profitability and that between leverage and market-to-book ratios, without relating to any asymmetric information and/or moral hazard considerations.

The rest of this paper is organized as follows. Section 2 develops the model wherein

\footnotetext{
${ }^{5}$ We generalize Blazenko's (1987) result from a binary random cash flow to a continuous random cash flow, and from a debt versus equity decision to a mix of debt and equity decision.
} 
a firm delegates its financing decision of a risky project to a manager who is both risk averse and regret averse. Section 3 characterizes the optimal capital structure chosen by the manager. Section 4 derives a closed-form solution in the case wherein the manager is solely regret averse and the project's risky cash flow is binary. The final section concludes.

\section{The model}

Consider a one-period model wherein a firm has assets in place and a risky project. The firm is initially all-equity financed. We assume complete capital markets in that all securities can be priced by the risk-neutral measure. As such, we can simply assume that shareholders and debt holders are risk neutral. The riskless rate of interest is known and, without any loss of generality, is normalized to zero.

The firm's project requires an investment amount, $I>0$, at the beginning of the period. The firm's assets in place can only be liquidated at the end of the period. We assume that the end-of-period value of the assets in place, $V_{0}$, is positive but less than $I$. The project, once undertaken, generates a stochastic cash flow, $\tilde{X}$, at date $1 .{ }^{6}$ The random variable, $\tilde{X}$, is distributed according to a known cumulative distribution function, $F(X)$, over support $[0, Z]$, where $Z>I$. Let $\mathrm{E}(\cdot)$ be the expectation operator with respect to $F(X)$, and $\bar{X}$ be the expected cash flow, $\mathrm{E}(\tilde{X})$. The project has positive net present value in that $\bar{X}>I$.

The firm can issue a mix of debt and equity to raise the investment cost, $I$, at the beginning of the period. The market value of the debt issued by the firm is given by

$$
B(D)=\int_{0}^{\max \left(D-V_{0}, 0\right)}\left(V_{0}+X\right) \mathrm{d} F(X)+\left\{1-F\left[\max \left(D-V_{0}, 0\right)\right]\right\} D,
$$

where $D$ is the face value of debt to be paid to debt holders at the end of the period. Let $D^{\circ}$ be the maximum face value at which $B\left(D^{\circ}\right)=I$. Since $\bar{X}>I$ and $V_{0}>0$, Eq. (1) implies that $D^{\circ}<Z$. Furthermore, Eq. (1) implies that $B^{\prime}(D)=1-F\left[\max \left(D-V_{0}, 0\right)\right]>0$

\footnotetext{
${ }^{6}$ Throughout the paper, random variables have a tilde $(\sim)$, while their realizations do not.
} 
for all $D \in\left[0, D^{\circ}\right]$.

To raise the remaining amount, $I-B(D)$, the firm issues additional shares to new shareholders. The fraction of the firm's equity value accrued to the new shareholders is equal to $[I-B(D)] /\left[V_{0}+\bar{X}-B(D)\right]$, and the existing shareholders' retained ownership is equal to

$$
\alpha(D)=\frac{V_{0}+\bar{X}-I}{V_{0}+\bar{X}-B(D)}
$$

The end-of-period wealth of the existing shareholders is, therefore, given by

$$
W(\tilde{X})=\alpha(D) \max \left(V_{0}+\tilde{X}-D, 0\right)
$$

where $\alpha(D)$ is given by Eq. (2). Differentiating Eq. (2) with respect to $D$ yields

$$
\alpha^{\prime}(D)=\alpha(D)\left\{\frac{1-F\left[\max \left(D-V_{0}, 0\right)\right]}{V_{0}+\bar{X}-B(D)}\right\}>0
$$

for all $D \in\left[0, D^{\circ}\right]$.

The existing shareholders delegate their decision making to a manager who receives compensation that is tied to their end-of-period wealth, $W$. Following Braun and Muermann (2004), Michenaud and Solnik (2008), and Wong (2014), we assume that the manager's preferences are represented by the following "modified" utility function that includes some compensation for regret:

$$
V(W)=(1-\gamma) U(W)-\gamma G\left(W^{\max }-W\right),
$$

where $\gamma \in[0,1]$ is a constant, $U(W)$ a von Neumann-Morgenstern utility function with $U^{\prime}(W)>0$ and $U^{\prime \prime}(W)<0$, and $G(R)$ is a regret function with $G(0)=0, G^{\prime}(R)>0$, and $G^{\prime \prime}(R)>0$. The regret, $R=W^{\max }-W$, is measured by the difference between the actual wealth, $W$, and the maximum wealth, $W^{\max }$, that the existing shareholders could have received at the end of the period should the manager have made the optimal 
financing decision based on knowing the project's true cash flow. Since $W$ cannot exceed $W^{\text {max }}$, the manager experiences disutility from forgoing the possibility of undertaking the ex-post optimal financing decision. The manager is solely risk averse or solely regret averse, depending on whether $\gamma=0$ or $\gamma=1$, respectively. As $\gamma$ increases, regret aversion becomes increasingly more important in representing the manager's preferences as compared to risk aversion.

To characterize the regret-averse manager's ex-ante optimal financing decision, we have to first determine the existing shareholders' maximum wealth at the end of the period, $W^{\max }(X)$, when the manager is privately informed about the project's true cash flow, $X$. Differentiating $\alpha(D)\left(V_{0}+X-D\right)$ with respect to $D$ yields

$$
\frac{\partial \alpha(D)\left(V_{0}+X-D\right)}{\partial D}=\alpha^{\prime}(D)\left[X-\mathrm{E}\left(\tilde{X} \mid \tilde{X} \geq \max \left(D-V_{0}, 0\right)\right]\right.
$$

Define $D(X) \geq V_{0}$ as the solution to $X=\mathrm{E}\left[\tilde{X} \mid \tilde{X} \geq D(X)-V_{0}\right]$. Then, we have $D(\bar{X})=V_{0}$, and $D(X)>V_{0}$ for all $X>\bar{X}$. Note that

$$
D^{\prime}(X)=\frac{1-F\left[D(X)-V_{0}\right]}{F^{\prime}\left[D(X)-V_{0}\right]\left[V_{0}+X-D(X)\right]}>0
$$

It follows from Eq. (7) that there is a critical cash flow, $X^{\circ} \in(\bar{X}, Z)$, at which $D\left(X^{\circ}\right)=D^{\circ}$. Hence, Eqs. (4) and (6) imply that

$$
W^{\max }(X)= \begin{cases}\alpha(0)\left(V_{0}+X\right) & \text { if } X \in[0, \bar{X}], \\ \alpha[D(X)]\left[V_{0}+X-D(X)\right] & \text { if } X \in\left(\bar{X}, X^{\circ}\right), \\ V_{0}+X-D^{\circ} & \text { if } X \in\left[X^{\circ}, Z\right] .\end{cases}
$$

Eq. (8) states that the privately informed manager issues no debt when default is likely, i.e., $X \in[0, \bar{X}]$, a mix of debt and equity when default is unlikely, i.e., $X \in\left(\bar{X}, X^{\circ}\right)$, and no equity when the upside is sufficiently high, i.e., $X \in\left[X^{\circ}, Z\right]$.

The regret-averse manager chooses the face value of the debt, $D$, so as to maximize the 
expected value of the modified utility function:

$$
\max _{D \in\left[0, D^{\circ}\right]} \operatorname{E}\left\{(1-\gamma) U[W(\tilde{X})]-\gamma G\left[W^{\max }(\tilde{X})-W(\tilde{X})\right]\right\}
$$

where $W(\tilde{X})$ and $W^{\max }(\tilde{X})$ are given by Eqs. (3) and (8), respectively. The first-order condition for program (9) is given by

$$
\begin{aligned}
& \alpha^{\prime}\left(D^{*}\right) \int_{\max \left(D^{*}-V_{0}, 0\right)}^{Z}\left\{(1-\gamma) U^{\prime}\left[\alpha\left(D^{*}\right)\left(V_{0}+X-D^{*}\right)\right]\right. \\
& \left.+\gamma G^{\prime}\left[W^{\max }(X)-\alpha\left(D^{*}\right)\left(V_{0}+X-D^{*}\right)\right]\right\} \\
& \times\left[X-\mathrm{E}\left(\tilde{X} \mid \tilde{X} \geq \max \left(D^{*}-V_{0}, 0\right)\right] \mathrm{d} F(X)=0,\right.
\end{aligned}
$$

where we have used Leibniz's rule, and $D^{*}$ is the optimal face value of the debt. Since $U^{\prime \prime}(W)<0$ and $G^{\prime \prime}(R)>0$, the second-order condition for program (9) is satisfied.

\section{Optimal capital structure}

As a benchmark, suppose that the manager is solely risk averse in that $\gamma=0$. Using Leibniz's rule, we differentiate $\mathrm{E}\{U[W(\tilde{X})]\}$ with respect to $D$ to yield

$$
\begin{aligned}
& \alpha^{\prime}(D) \int_{\max \left(D-V_{0}, 0\right)}^{Z} U^{\prime}\left[\alpha(D)\left(V_{0}+X-D\right)\right]\left[X-\mathrm{E}\left(\tilde{X} \mid \tilde{X} \geq \max \left(D-V_{0}, 0\right)\right] \mathrm{d} F(X)\right. \\
& =\alpha^{\prime}(D)\left\{1-F\left[\max \left(D-V_{0}, 0\right)\right]\right\} \\
& \quad \times \operatorname{Cov}\left\{U^{\prime}\left[\alpha(D)\left(V_{0}+\tilde{X}-D\right)\right], \tilde{X} \mid \tilde{X} \geq \max \left(D-V_{0}, 0\right)\right\},
\end{aligned}
$$

where $\operatorname{Cov}(\cdot, \cdot)$ is the covariance operator with respect to $F(X)$. Since $U^{\prime \prime}(W)<0$, the right-hand side of Eq. (11) is negative for all $D \in\left[0, D^{\circ}\right]$ given Eq. (4). We as such establish our first proposition. 
Proposition 1. If the manager is solely risk averse, the optimal capital structure chosen by the manager has zero debt, i.e., $D^{*}=0$.

To see the intuition for Proposition 1, we use the change-of-variable technique (Hogg and Craig, 1989) to write

$$
\mathrm{E}\{U[W(\tilde{X})]\}=\int_{\alpha(D) \max \left(V_{0}-D, 0\right)}^{\alpha(D)\left(V_{0}+Z-D\right)} U(W) \mathrm{d} G(W)
$$

where $G(W)=F\left[D-V_{0}+W / \alpha(D)\right]$ for all $W \in\left[\alpha(D) \max \left(V_{0}-D, 0\right), \alpha(D)\left(V_{0}+Z-D\right)\right]$, and $D \in\left[0, D^{\circ}\right]$. Consider the following function:

$$
T(W)=\frac{\partial}{\partial D}\left[\int_{\alpha(D) \max \left(V_{0}-D, 0\right)}^{W} G(Y) \mathrm{d} Y\right]
$$

for all $W \in\left[\alpha(D) \max \left(V_{0}-D, 0\right), \alpha(D)\left(V_{0}+Z-D\right)\right]$. In Appendix A, we show that $T(W)>$ 0 if $\alpha(D) \max \left(V_{0}-D, 0\right)<W<\alpha(D)\left(V_{0}+Z-D\right)$ and that $T\left[\alpha(D)\left(V_{0}+Z-D\right)\right]=0$. Hence, an increase in $D$ constitutes a mean-preserving-spread increase in risk in the sense of Rothschild and Stiglitz (1970) for all $D \in\left[0, D^{\circ}\right]$. The manager, being risk averse, finds it optimal not to use any debt so as to minimize the variability of the existing shareholders' end-of-period wealth (Rothschild and Stiglitz, 1971). This result is consistent with the zeroleverage behavior prevalent in the U.S. (Strebulaev and Yang, 2013) and in many developed countries (Bessler et al., 2013).

We now resume the original case that the manager is regret averse in that $\gamma \in(0,1]$. In the following proposition, we derive a sufficient condition under which the regret-averse manager optimally uses a mix of debt and equity to finance the risky project.

Proposition 2. If regret aversion is relatively more important than risk aversion in representing the manager's preferences in that the coefficient, $\gamma$, satisfies that

$$
\gamma>\frac{\operatorname{Cov}\left\{U^{\prime}\left[\alpha(0)\left(V_{0}+\tilde{X}\right)\right], \tilde{X}\right\}}{\operatorname{Cov}\left\{U^{\prime}\left[\alpha(0)\left(V_{0}+\tilde{X}\right)\right]-G^{\prime}\left[W^{\max }(\tilde{X})-\alpha(0)\left(V_{0}+\tilde{X}\right)\right], \tilde{X}\right\}},
$$


the optimal capital structure chosen by the regret-averse manager contains a mix of debt and equity, i.e., $D^{*} \in\left(0, D^{\circ}\right)$. Furthermore, the firm's market leverage ratio, $L R=B\left(D^{*}\right) /\left(V_{0}+\right.$ $\bar{X})$, increases when regret aversion becomes increasingly more important than risk aversion in representing the manager's preferences, i.e., $\partial L R / \partial \gamma>0$.

Proof. See Appendix B.

To see the intuition for Proposition 2, we write Eq. (10) as

$$
\begin{aligned}
& (1-\gamma) \operatorname{Cov}\left\{U^{\prime}\left[\alpha\left(D^{*}\right)\left(V_{0}+\tilde{X}-D^{*}\right)\right], \tilde{X} \mid \tilde{X} \geq \max \left(D^{*}-V_{0}, 0\right)\right\} \\
& +\gamma \operatorname{Cov}\left\{G^{\prime}\left[W^{\max }(\tilde{X})-\alpha\left(D^{*}\right)\left(V_{0}+\tilde{X}-D^{*}\right)\right], \tilde{X} \mid \tilde{X} \geq \max \left(D^{*}-V_{0}, 0\right)\right\}=0 .
\end{aligned}
$$

Inspection of Eq. (15) reveals that the manager chooses the optimal face value, $D^{*}$, to jointly minimize the variability of the existing shareholders' end-of-period wealth, $W^{*}(\tilde{X})$, and the variability of the manager's regret, $W^{\max }(\tilde{X})-W^{*}(\tilde{X})$. The risk-minimizing incentive induces the manager to opt for zero leverage (see Proposition 1). The regret-minimizing incentive, on the other hand, induces the manager to avoid making extreme financing decisions. ${ }^{7}$ As such, the manager, being sufficiently more regret averse than risk averse in that condition (14) holds, optimally issues a mix of debt and equity to finance the risky project. An increase in the coefficient, $\gamma$, makes regret aversion increasingly more important than risk aversion in representing the manager's preferences. This strengthens the regret-minimizing incentive and concomitantly weakens the risk-minimizing incentive, as is evident from Eq. (15). As a result, the firm's market leverage ratio, $L R=B\left(D^{*}\right) /\left(V_{0}+\bar{X}\right)$, goes up in response to an increase in $\gamma$.

Using a manager-firm matched panel data, Bertrand and Schoar (2003) find that older generations of CEOs tend to choose lower levels of financial leverage. Specifically, each ten-year increase in CEO year of birth increases financial leverage by 2.5 percent. Since

\footnotetext{
${ }^{7}$ When the manager is solely regret averse in that $\gamma=1$, condition (14) holds so that $D^{*} \in\left(0, D^{\circ}\right)$.
} 
increases in CEO year of birth are negatively associated with CEO experience, decisions made by older generations of $\mathrm{CEO}$ are more likely to be driven by risk aversion than by regret aversion, which is consistent with the results of Proposition 2.

\section{A closed-form solution}

In this section, we consider the case wherein the manager is solely regret averse in that $\gamma=1$. The project's risky cash flow, $\tilde{X}$, is binary in that $\tilde{X}$ takes on only two possible values: $Z$ if the project succeeds, and 0 if the project fails. Let $p \in(0,1)$ be the probability that $X=Z$. Under this binary specification, $\bar{X}=p Z, B(D)=p D+(1-p) \min \left(V_{0}, D\right)$, and $D^{\circ}=V_{0}+\left(I-V_{0}\right) / p$. Eq. (8) becomes

$$
W^{\max }(X)= \begin{cases}\alpha(0) V_{0} & \text { if } X=0 \\ V_{0}+Z-D^{\circ} & \text { if } X=Z\end{cases}
$$

The existing shareholders' end-of-period wealth is given by $W(Z)=\alpha(D)\left(V_{0}+Z-D\right)$ and $W(0)=\alpha(D) \max \left(V_{0}-D, 0\right)$ for all $D \in\left[0, D^{\circ}\right]$.

If $D>V_{0}$, we have $B(D)=p D+(1-p) V_{0}$ and $\alpha(D)=\left(V_{0}+p Z-I\right) / p\left(V_{0}+Z-D\right)$. In this case, $W(Z)=\left(V_{0}+p Z-I\right) / p$ and $W(0)=0$, both of which are independent of $D .{ }^{8}$ Hence, the optimal face value, $D^{*}$, must not exceed $V_{0}$. The first-order condition, Eq. (10), as such reduces to

$$
G^{\prime}\left[W^{\max }(Z)-\alpha\left(D^{*}\right)\left(V_{0}+Z-D^{*}\right)\right]-G^{\prime}\left[W^{\max }(0)-\alpha\left(D^{*}\right)\left(V_{0}-D^{*}\right)\right]=0 .
$$

Eq. (17) implies that, at the optimum, the manager equates the magnitude of regret in the successful state, $W^{\max }(Z)-\alpha\left(D^{*}\right)\left(V_{0}+Z-D^{*}\right)$, to that in the failure state, $W^{\max }(0)-$ $\alpha\left(D^{*}\right)\left(V_{0}-D^{*}\right)$, thereby completely smoothing regret between the two states. Solving for

\footnotetext{
${ }^{8} \mathrm{In}$ a two-state setting, it is well-known that outside equity and risky debt are observationally equivalent.
} 
$D^{*}$ yields

$$
D^{*}=\left[1-\frac{p^{2} Z}{(1-p) V_{0}+p Z}\right] V_{0}
$$

which is indeed less than $V_{0}$.

Using Eq. (18), we can write the firm's market leverage ratio, $L R=D^{*} /\left(V_{0}+p Z\right)$, as

$$
L R=\frac{(1-p) V_{0}}{(1-p) V_{0}+p Z}
$$

The market-to-book ratio of the firm, $M / B$, is defined by the ratio of the market value of the firm's assets (i.e., the market value of the firm) to the book value of the firm's assets (i.e., the value of the assets in place) so that $M / B=\left(V_{0}+p Z\right) / V_{0}$. Using $M / B$, we can write Eq. (19) as

$$
L R=\frac{1-p}{M / B-p}
$$

In the following proposition, we use Eqs. (19) and (20) to derive comparative statics of $L R$ with respect to the model's key parameters, $Z, p$, and $M / B$.

Proposition 3. If the manager is solely regret averse and the project's risky cash flow is binary, the firm's market leverage ratio, LR, decreases as the project becomes more profitable (represented by an increase in either the project's successful cash flow, Z, or the probability of success, $p$ ), and as the firm's market-to-book ratio, $M / B$, increases.

Proof. See Appendix C.

The intuition for Proposition 3 is as follows. When the risky project becomes more profitable in that either $Z$ or $p$ increases, the existing shareholder's end-of-period wealth must be closer to (further away from) the maximum wealth should the project succeed (fail). To minimize regret, the manager optimally issues less debt so as to lower the magnitude of 
regret in the failure state and raise that in the successful state until these two magnitudes are equalized. Since the firm value, $V_{0}+p Z$, increases while the debt value, $D^{*}$, decreases as the project becomes more profitable, the firm's market leverage ratio, $L R$, goes down. This result is consistent with the robust evidence of an inverse relation between leverage and profitability as documented in the literature on empirical capital structure (Graham and Leary, 2011).

An increase in the firm's market-to-book ratio, $M / B$, may be due to an increase in the expected project value, $p Z$, or a decrease in the value of the assets in place, $V_{0}$. In the former case, the intuition for the inverse relation between leverage and profitability applies. In the latter case, a decrease in $V_{0}$ implies a reduction in the initial equity base and thus less retained ownership held by the existing shareholders. Hence, the existing shareholder's end-of-period wealth must be closer to (further away from) the maximum wealth when the project succeed (fail), in which case debt (equity) should be used. To minimize regret, the manager optimally issues less debt so as to raise the magnitude of regret in the successful state and lower that in the failure state until these two magnitudes are equalized. Since the debt value, $D^{*}$, decreases by a greater extent than the firm value, $V_{0}+p Z$, as $V_{0}$ decreases, the firm's market leverage ratio, $L R$, goes down. This result is consistent with the widely documented inverse relation between leverage and market-tobook ratios (Graham and Leary, 2011).

\section{Conclusion}

In this paper, we examine the optimal capital structure of a firm that delegates its financing decision of a risky project to a manager who is not only risk averse but also regret averse. Following the regret-theoretical approach of Braun and Muermann (2004), Michenaud and Solnik (2008), and Wong (2014), we characterize the manager's regretaverse preferences by a utility function that includes disutility from having chosen ex-post 
suboptimal alternatives. We show that managerial risk aversion alone gives rise to a riskminimizing incentive that calls for all-equity financing, which is consistent with the zeroleverage phenomenon widely observed in the U.S. (Strebulaev and Yang, 2013) and in many developed countries (Bessler et al., 2013). We further show that regret aversion gives rise to a regret-minimizing incentive that induces the manager to avoid making extreme financing decisions. When both risk aversion and regret aversion prevail, the firm's optimal capital structure is jointly determined by the risk-minimizing and regret-minimizing incentives, thereby rendering an interior solution solely driven by managerial preferences. Finally, we show that the inverse relation between leverage and profitability and that between leverage and market-to-book ratios, both of which are widely documented in the literature on empirical capital structure (Graham and Leary, 2011), prevail in our model. Managerial regret-averse preferences as such provide a useful behavioral approach to the theories of capital structure.

\section{Appendix A. Mean-preserving-spreads of $G(W)$}

Using Leibniz's rule, we can write Eq. (13) as

$$
\begin{aligned}
T(W) & =\frac{1}{\alpha(D)} \int_{\alpha(D) \max \left(V_{0}-D, 0\right)}^{W}\left\{1-\left\{\frac{1-G\left[\alpha(D) \max \left(V_{0}-D, 0\right)\right]}{V_{0}+\bar{X}-I}\right\} Y\right\} \mathrm{d} G(Y) \\
& =\frac{1}{\alpha(D)}\left\{\frac{G(W)-G\left[\alpha(D) \max \left(V_{0}-D, 0\right)\right]}{V_{0}+\bar{X}-I}\right\}\left[V_{0}+\bar{X}-I-\Theta(W)\right],
\end{aligned}
$$

where the function, $\Theta(W)$, is given by

$$
\Theta(W)=\frac{1-G\left[\alpha(D) \max \left(V_{0}-D, 0\right)\right]}{G(W)-G\left[\alpha(D) \max \left(V_{0}-D, 0\right)\right]} \int_{\alpha(D) \max \left(V_{0}-D, 0\right)}^{W} Y \mathrm{~d} G(Y)
$$

It is evident from Eq. (A.2) that $\Theta\left[\alpha(D)\left(V_{0}+Z-D\right)\right]=V_{0}+\bar{X}-I$. It then follows from Eq. (A.1) that $T\left[\alpha(D)\left(V_{0}+Z-D\right)\right]=0$. Using Leibniz's rule, we differentiate Eq. (A.2) 
with respect to $W$ to yield

$$
\Theta^{\prime}(W)=\frac{\left\{1-G\left[\alpha(D) \max \left(V_{0}-D, 0\right)\right]\right\} G^{\prime}(W)\left[W-\mathrm{E}_{G}(\tilde{W} \mid \tilde{W} \leq W)\right]}{G(W)-G\left[\alpha(D) \max \left(V_{0}-D, 0\right)\right]}>0
$$

where $\mathrm{E}_{G}(\cdot)$ is the expectation operator with respect to $G(W)$. It then follows from Eq. (A.3) that $\Theta(W)<V_{0}+\bar{X}-I$ for all $W<\alpha(D)\left(V_{0}+Z-D\right)$. Hence, Eq. (A.1) implies that $T(W)>0$ whenever $\alpha(D) \max \left(V_{0}-D, 0\right)<W<\alpha(D)\left(V_{0}+Z-D\right)$. In words, an increase in $D$ constitutes a mean-preserving-spread increase in risk in the sense of Rothschild and Stiglitz (1970) for all $D \in\left[0, D^{\circ}\right]$.

\section{Appendix B. Proof of Proposition 2}

Differentiating the objective function of program (9) with respect to $D$, and evaluating the resulting derivative at $D=0$ yields

$$
\begin{aligned}
& \alpha^{\prime}(0) \int_{0}^{Z}\left\{(1-\gamma) U^{\prime}\left[\alpha(0)\left(V_{0}+X\right)\right]+\gamma G^{\prime}[\Phi(X)]\right\}(X-\bar{X}) \mathrm{d} F(X) \\
& =\alpha^{\prime}(0) \operatorname{Cov}\left\{(1-\gamma) U^{\prime}\left[\alpha(0)\left(V_{0}+\tilde{X}\right)\right]+\gamma G^{\prime}[\Phi(\tilde{X})], \tilde{X}\right\},
\end{aligned}
$$

where $\Phi(X)=W^{\max }(X)-\alpha(0)\left(V_{0}+X\right)$. Using Eq. (8), we have

$$
\Phi^{\prime}(X)= \begin{cases}0 & \text { if } X \in[0, \bar{X}], \\ \alpha[D(X)]-\alpha(0) & \text { if } X \in\left(\bar{X}, X^{\circ}\right), \\ 1-\alpha(0) & \text { if } X \in\left[X^{\circ}, Z\right] .\end{cases}
$$

Eq. (A.5) implies that $\Phi(X)$ is non-decreasing in $X$. It then follows from $G^{\prime \prime}(R)>0$ that $\operatorname{Cov}\left\{G^{\prime}[\Phi(\tilde{X})], \tilde{X}\right\}>0$. Since $\operatorname{Cov}\left\{U^{\prime}\left[\alpha(0)\left(V_{0}+\tilde{X}\right)\right], \tilde{X}\right\}<0$, the right-hand side of Eq. (A.4) is positive given that condition (14) holds. Eq. (10) and the second-order condition for program (9) then imply that $D^{*}>0$. 
Differentiating the objective function of program (9) with respect to $D$, and evaluating the resulting derivative at $D=D^{\circ}$ yields

$$
\begin{aligned}
& \alpha^{\prime}\left(D^{\circ}\right) \int_{D^{\circ}-V_{0}}^{Z}\left\{(1-\gamma) U^{\prime}\left(V_{0}+X-D^{\circ}\right)\right. \\
& \left.\quad+\gamma G^{\prime}[\Psi(X)]\right\}\left[X-\mathrm{E}\left(\tilde{X} \mid \tilde{X} \geq D^{\circ}-V_{0}\right)\right] \mathrm{d} F(X) \\
& =\alpha^{\prime}\left(D^{\circ}\right)\left[1-F\left(D^{\circ}-V_{0}\right)\right] \\
& \quad \times \operatorname{Cov}\left\{(1-\gamma) U^{\prime}\left(V_{0}+\tilde{X}-D^{\circ}\right)+\gamma G^{\prime}[\Psi(\tilde{X})], \tilde{X} \mid \tilde{X} \geq D^{\circ}-V_{0}\right\},
\end{aligned}
$$

where $\Psi(X)=W^{\max }(X)-V_{0}-X+D^{\circ}$. Using Eq. (8), we have

$$
\Psi^{\prime}(X)= \begin{cases}\alpha(0)-1 & \text { if } X \in[0, \bar{X}], \\ \alpha[D(X)]-1 & \text { if } X \in\left(\bar{X}, X^{\circ}\right), \\ 0 & \text { if } X \in\left[X^{\circ}, Z\right] .\end{cases}
$$

Eq. (A.7) implies that $\Psi(X)$ is non-increasing in $X$. It then follows from $G^{\prime \prime}(R)>0$ that $\operatorname{Cov}\left\{G^{\prime}[\Psi(\tilde{X})], \tilde{X}\right\}<0$. Since $\operatorname{Cov}\left[U^{\prime}\left(V_{0}+\tilde{X}-D^{\circ}\right), \tilde{X}\right]<0$, the right-hand side of Eq. (A.6) is negative. Eq. (10) and the second-order condition for program (9) then imply that $D^{*}<D^{\circ}$.

Differentiating Eq. (10) with respect to $\gamma$ yields

$$
\begin{aligned}
& \frac{\partial D^{*}}{\partial \gamma}=\frac{\alpha^{\prime}\left(D^{*}\right)}{\gamma}\left\{1-F\left[\max \left(D^{*}-V_{0}, 0\right)\right]\right\} \\
& \times \operatorname{Cov}\left\{U^{\prime}\left[\alpha\left(D^{*}\right)\left(V_{0}+\tilde{X}-D^{*}\right)\right], \tilde{X} \mid \tilde{X} \geq \max \left(D^{*}-V_{0}, 0\right)\right\} /\left.\frac{\partial^{2} \mathrm{E}[V(\tilde{W})]}{\partial D^{2}}\right|_{D=D^{*}}
\end{aligned}
$$

where we have used Eq. (10). It follows from the second-order condition for program (9), Eq. (4), and $U^{\prime \prime}(W)<0$ that the right-hand side of Eq. (A.8) is positive. Differentiating $L R=B\left(D^{*}\right) /\left(V_{0}+\bar{X}\right)$ with respect to $\gamma$ yields

$$
\frac{\partial L R}{\partial \gamma}=\left\{\frac{1-F\left[\max \left(D^{*}-V_{0}, 0\right)\right]}{V_{0}+\bar{X}}\right\} \frac{\partial D^{*}}{\partial \gamma}>0,
$$


where the inequality follows from Eq. (A.8).

\section{Appendix C. Proof of Proposition 3}

Differentiating Eq. (19) with respect to $Z$ and $p$ yields

$$
\frac{\partial L R}{\partial Z}=-\frac{p(1-p) V_{0}}{\left[(1-p) V_{0}+p Z\right]^{2}}<0,
$$

and

$$
\frac{\partial L R}{\partial p}=-\frac{Z V_{0}}{\left[(1-p) V_{0}+p Z\right]^{2}}<0 .
$$

Differentiating Eq. (20) with respect to $M / B$ yields

$$
\frac{\partial L R}{\partial M / B}=-\frac{1-p}{(M / B-p)^{2}}<0 .
$$

\section{References}

Almeida, H., Philippon, T., 2007. The risk-adjusted cost of financial distress. Journal of Finance 62, 2557-2586.

Bell, D. E., 1982. Regret in decision making under uncertainty. Operations Research 30, 961-981.

Bell, D. E., 1983. Risk premiums for decision regret. Management Science 29, 1156-1166.

Bertrand, M., Schoar, A., 2003. Managing with style: The effect of managers on firm policies. Quarterly Journal of Economics 118, 1169-1208.

Bessler, W., Drobetz, W., Haller, R, Meier, I., 2013. The international zero-leverage phenomenon. Journal of Corporate Finance 23, 196-221. 
Blazenko, G. W., 1987. Managerial preferences, asymmetric information, and financial structure. Journal of Finance 42, 839-862.

Bleichrodt, H., Cillo, A., Diecidue, E., 2010. A quantitative measurement of regret theory. Management Science 56, 161-175.

Braun, M., Muermann, A., 2004. The impact of regret on the demand for insurance. Journal of Risk and Insurance 71, 737-767.

Chen, H., 2010. Macroeconomic conditions and the puzzles of credit spreads and capital structure. Journal of Finance 65, 2171-2212.

Chen, H., Miao, J., Wang, N., 2010. Entrepreneurial finance and nondiversifiable risk. Review of Financial Studies 23, 4348-4388.

Graham, J. R., 2000. How big are the tax benefits of debt? Journal of Finance 55, 19011941.

Graham, J. R., Harvey, C. R., Puri, M., 2013. Managerial attitudes and corporate actions. Journal of Financial Economics 109, 103-121.

Graham, J. R., Leary, M. T., 2011. A review of empirical capital structure research and directions for the future. Annal Review of Financial Economics 3, 309-345.

Hackbarth, D., 2008. Managerial traits and capital structure decisions. Journal of Financial and Quantitative Analysis 43, 843-881.

Hackbarth, D., 2009. Determinants of corporate borrowing: A behavioral perspective. Journal of Corporate Finance 15, 389-411.

Hogg, R. V., Craig, A. T., 1989. Introduction to mathematical statistics (4th ed.). New York: Macmillan.

Korteweg, A., 2010. The net benefits to leverage. Journal of Finance 65, 2137-2170.

Loomes, G., 1988. Further evidence of the impact of Regret and disappointment in choice under uncertainty. Economica 55, 47-62. 
Loomes, G., Starmer, C., Sugden, R., 1992. Are preferences monotonic-Testing some predictions of regret theory. Economica 59, 17-33.

Loomes, G., Sugden, R., 1982. Regret theory: An alternative theory of rational choice under uncertainty. Economic Journal 92, 805-824.

Loomes, G., Sugden, R., 1987. Testing for regret and disappointment in choice under uncertainty. Economic Journal 97, 118-129.

Malmendier, U., Tate, G., Yan, J., 2011. Overconfidence and early-life experiences: The effect of managerial traits on corporate financial policies. Journal of Finance 66, 16871733.

Michenaud, S., Solnik, B., 2008. Applying regret theory to investment choices: Currency hedging decisions. Journal of International Money and Finance 27, 677-694.

Modigliani, F., Miller, M. H., 1958. The cost of capital, corporation finance and the theory of investment. American Economic Review 48, 261-297.

Molina, C., 2005. Are firms underleveraged? An examination of the effect of leverage on default probabilities. Journal of Finance 60, 1427-1459.

Myers, S. C., 1993. Still searching for optimal capital structure. Journal of Applied Corporate Finance 6, 4-14.

Quiggin, J., 1994. Regret theory with general choice sets. Journal of Risk and Uncertainty $8,153-165$.

Ross, S. A., 1977. The determination of capital structure: the incentive signalling approach. Bell Journal of Economics 8, 23-40.

Ross, S. A., 1978. Some notes on financial-incentive signalling models, activity choice and risk preferences. Journal of Finance 33, 777-792.

Rothschild, M., Stiglitz, J. E., 1970. Increasing risk: I. A definition. Journal of Economic Theory $2,225-243$. 
Rothschild, M., Stiglitz, J. E., 1971. Increasing risk II: Its economic consequences. Journal of Economic Theory 3, 66-84.

Starmer, C., Sugden, R., 1993. Testing for juxtaposition and event-splitting effects. Journal of Risk and Uncertainty 6, 235-254.

Steil, B., 1993. Corporate foreign exchange risk management: A study in decision making under uncertainty. Journal of Behavioral Decision Making 6, 1-31.

Strebulaev, I. A., Yang, B., 2013. The mystery of zero-leverage firms. Journal of Financial Economics 109, 1-23.

Sugden, R., 1993. An axiomatic foundation of regret. Journal of Economic Theory 60, $159-180$.

Wong, K. P., 2014. Regret theory and the competitive firm. Economic Modelling 36, $172-175$. 